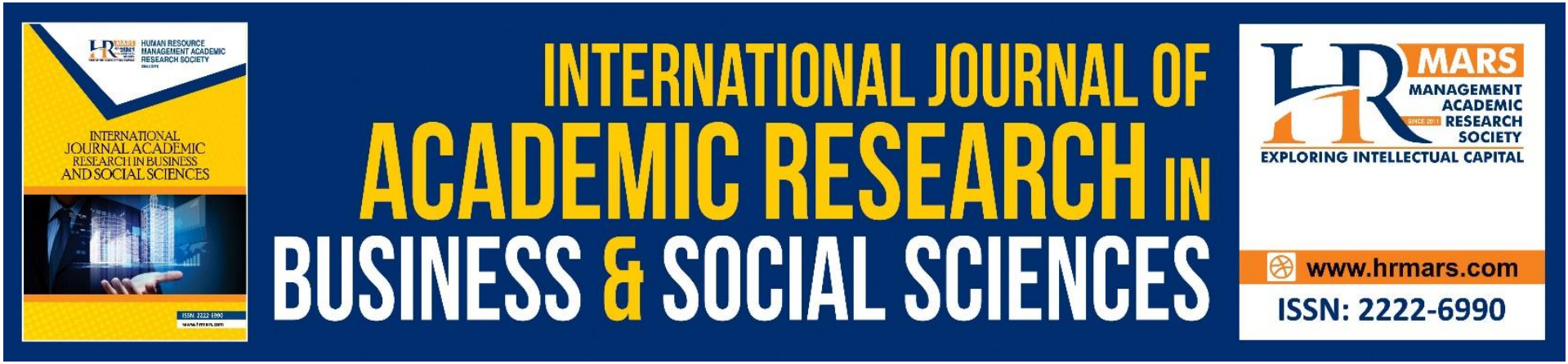

\title{
Roles of Customer Satisfaction and Customer Perceptions in Relationships between The Emotional Labor Performance
}

Noha Anan

To Link this Article: http://dx.doi.org/10.6007/IJARBSS/v11-i3/9098

DOI:10.6007/IJARBSS/v11-i3/9098

Received: 01 January 2021, Revised: 26 January 2021, Accepted: 15 February 2021

Published Online: 24 March 2021

In-Text Citation: (Anan, 2021)

To Cite this Article: Anan, N. (2021). Roles of Customer Satisfaction and Customer Perceptions in Relationships between The Emotional Labor Performance. International Journal of Academic Research in Business and Social Sciences, 11(3), 1061-1079.

Copyright: (C) 2021 The Author(s)

Published by Human Resource Management Academic Research Society (www.hrmars.com)

This article is published under the Creative Commons Attribution (CC BY 4.0) license. Anyone may reproduce, distribute, translate and create derivative works of this article (for both commercial and non-commercial purposes), subject to full attribution to the original publication and authors. The full terms of this license may be seen at: http://creativecommons.org/licences/by/4.0/legalcode

Vol. 11, No. 3, 2021, Pg. 1061 - 1079

http://hrmars.com/index.php/pages/detail/IJARBSS

JOURNAL HOMEPAGE

Full Terms \& Conditions of access and use can be found at http://hrmars.com/index.php/pages/detail/publication-ethics 


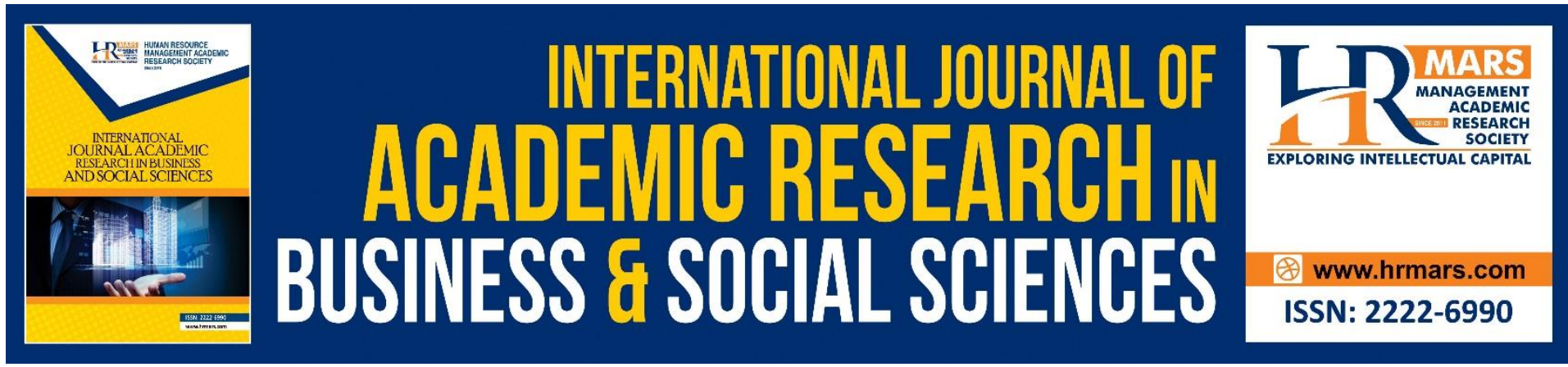

\title{
Roles of Customer Satisfaction and Customer Perceptions in Relationships between The Emotional Labor Performance
}

\author{
Noha Anan \\ Professor of Human Resource Management, Business administration department, Faculty of \\ Business and Economics, Badr University, Egypt. \\ Email: noha.adel @buc.edu.eg
}

\begin{abstract}
This paper presents an analysis of the relationships of Customer satisfaction and customer perceptions in higher education on emotional employee's performance. To gather information, questionnaires were applied to 670 students distributed in the Fucalty of Business and Economics at Badr University. The researcher used the methodology of correlation that explains such effects. The results show that when there is a high level of deep acting, this affects the customer satisfaction positively. The researcher also found that the customer perception has positively related to deep acting while surface acting has negative relationships to both customer satisfaction and customer perceptions.
\end{abstract}

Keywords: Customer Satisfaction, Customer Perceptions, Emotional Labor, Deep Acting, Surface Acting

\section{Introduction}

All over the world, professors and teaching assistants occupy a central role in the delivery of quality higher education to students. Unfortunately, there has been increasing evidence to suggest that they face many problems while discharging their duties that may affect their performance as emotional labors.

Research on emotional labor has shown that displaying positive emotions in service interactions, such as smiling and conveying friendliness, is positively associated with the intention of customers to return, with their intention to recommend the service to others, and with the overall perception of service quality (e.g., Pugh 2001). The findings concluded that the more positive emotions are displayed in service interactions, the higher the satisfaction of customers will be. Such positive emotions could be developed and displayed when service providers modified their inner feelings to match the required expressions (deep acting) (e.g., Pugh 2001).

Performing emotional labor requires effort and presents an occupational demand. This management of emotions in the context of work is recognized as a labor process that is sold for a wage and, therefore, is commoditized and has exchange value (Hochschild, 1983). 
Emotional labor because it possesses an aspect of control over workers, can result in negative psychosocial outcomes such as job stress and burnout and dissatisfaction. More specifically, emotional labor creates routinized, processed feelings and emotional dissonance that threaten workers' sense of self, dislike workers from their true feelings, and produce an impression of "inauthenticity" (Hochschild et al., 1983). Because emotional labor occurs in jobs involving direct contact with customers, service work sometimes entails interactions with angry, hostile, or uncooperative customers. These interactions can be emotionally charged and a source of increased demand (Morris et al., 1996).

Interactive service workers engage in emotional labor through two methods: surface acting, by pretending or regulating one's emotional expressions; and deep acting, by consciously modifying one's emotions to express a desired emotion (Grandey et al., 2000).

Distinction between these methods are considered critical with respect to the consequences of carrying out emotional labor. As (Hochschild, 1983) originally described, surface acting is associated with inauthenticity which in turn reflects the dissonance between emotions truly felt by the service worker and those that must be expressed according to organizational expectations mandated onto service interactions.

In this study, the researcher aims to investigate the relationships between professors and teaching assistants' performance in Badr University and the student's satisfaction and their perceptions of the work performance of their professors and teaching assistants.

With few exceptions (e.g. Moon et al., 2013), most previous studies have focused on coworker or supervisor support. Little is however known concerning whether emotional labor has an effect on the students' satisfaction and their perception of their professor's performance, so this study is going to fill this gap.

\section{Problem Definition}

In this paper, the researcher presents the results of a quantitative study on the question whether the emotional labor performance has a relationship with customer satisfaction and perception or not using a convenience sample. It draws on data from multiple sources. This study was carried out in the Faculty of Business and Economics at Badr University in Egypt .Thus, the problem of this study can be identified in a key research question, which is: "What is the relationships between customer satisfaction, customer perception and the emotional labor performance?"

\section{Research Objective}

To investigate the emotional labor performance of the professors and teaching assistants of the Faculty of Business and Economics at Badr University in Egypt by using customer satisfaction and customer perception of the work performance of employees as sources of performance rating.

\section{Research Importance}

This research primarily seeks to examine emotional labor performance affects customer satisfaction and perceptions of work performance. While professors and teaching assistants are required to do much interaction with students, they are expected to ensure the orderly 
self-conduct (e.g., be warm and polite to students) throughout the day, every working day. The researcher seeks to detect any conflicts between required and true performance following strict regulation of their emotions and to determine how significant the conflicts might be for customer satisfaction and perceptions for professors and teaching assistants, whose jobs demand a high degree of emotional display. In addition, as educational service providers have to show or exaggerate some emotions and minimize or suppress the expression of unfriendly emotions. Professors and teaching assistants may easily feel inconsistencies between their true feelings and displayed emotions.

In addition, although there has been a rush of interest in emotional labor customer satisfaction, as they continue to appear as core concepts in recent organizational behavior studies these concepts appear to be somewhat in immature stage in the higher educational context.

Therefore, The second aim of this study is to investigate the relationship between Professors and teaching assistants emotional labor and the intensity of students satisfaction and perception they experience.

Next to investigate the emotional labor-customer satisfaction and perceptions relation, the present study also aims to extend emotional labor research by focusing on the potential moderating role of customer satisfaction and perceptions in this relationship.

Accordingly, the third aim of the present study is to examine whether emotional labor helps professors moderate the impact of the emotional labor inherent in their job. Because customer satisfaction has major significance for both employees and organizations, it is thus crucial to continue searching for mechanisms and strategies by which professors can reduce the harmful impacts of emotional labor. The present study thus, further contributes to the literature by attempting to deepen our understanding of the emotional labor that can explain when and how emotional labor may result to customer satisfaction specifically in higher education as educational service providers' organizations.

\section{Literature Review}

\section{Previous studies on Emotional Labor Performance}

(Ji Wena et al. ,2019) examined the effects of emotional intelligence and emotional labor on job satisfaction in a moderated mediation model, which posits surface and deep acting strategies as mediators between emotional intelligence and job satisfaction and perceived organizational support as a moderator to the mediation effects. Based on a sample of 279 Chinese hotel employees, results showed that while deep acting partially mediated the effect of emotional intelligence on job satisfaction, surface acting did not mediate; and also, Perceived organizational support effectively moderated the mediation of deep acting between emotional intelligence and job satisfaction; but the moderated mediation was not found with surface acting as a mediator. The study contributes to a better understanding of the roles of emotional intelligence and emotional labor strategies in affecting hotel employees' job satisfaction and how organizational support can function as an organization resource in changing the psychological mechanisms underlying emotional labor and job satisfaction. 
(Wang, 2019), the study was based on the job demands -resources model (Bakker et al., 2004) and conservation of resources theory (Hobfall, 2001) by using three levels of variables, namely, company (i.e., perceived organizational support), department (i.e., abusive supervision), and employee (i.e., deep acting, surface acting, and self-efficacy) levels, to investigate its interactions with contextual influences on service quality and its linkage with customer loyalty. A three-level hierarchical linear model were examined in research settings by using a couple data set of 1,082 service employees and customers in international tourist hotels. Findings revealed that deep acting as an emotional labor strategy relates positively to service quality while, surface acting as another emotional labor strategy relates negatively to service quality, and service quality relates positively to customer loyalty. For the three-level interactions, the positive relationship between deep acting and service quality was strengthened by perceived organizational support (POS) and self-efficacy but weakened by abusive supervision. By contrast, the negative relationship between surface acting and service quality was mitigated by POS and self-efficacy but exacerbated by abusive supervision. The study contributed to the importance of emotional labor research in the hospitality industry and to the areas of service quality and customer loyalty and also, suggests future directions for hospitality research.

(Riaz et al., 2018) examined the effect of perceived organizational support on emotional labor with the mediating role of emotional intelligence. Questionnaire survey method was adapted and data were collected from 370 employees of telecommunication sector through Simple Random Sampling Technique. Hypotheses were tested and analyzed by AMOS. Results showed that POS positively affects deep Acting but has a negative impact on surface acting. Results enlightened that emotional intelligence significantly mediates the relationship between perceived organizational support and emotional labor. The study also revealed the significant relationship of emotional labor and counterproductive work behavior. Surface acting positively and significantly effect on counterproductive work behavior whereas deep acting influence negatively on counterproductive work behavior. Findings also disclosure that the relationship of emotional labor and counterproductive work behavior is significantly moderated by emotional intelligence

(Jamshed, 2018) developed a conceptual understanding on two major perspectives that makes the sense of teams becoming emotionally intelligent by focusing how individuals apprehend the emotions they possess and simultaneously emotions of their team members via strengthening their emotional capacity that ultimately leads them to the higher level of performance. The author assured that across the globe individuals' that embraced emotionally intelligence are working individuals who strive hard to develop and practice emotional intelligence skills to be effective team members.

(Kima, 2017) examined the moderating roles of perceived supervisor, coworker, and organizational support in the relationship between emotional labor and job performance in the airline service context. A sample of flight attendants working for one major airline company in South Korea participated in this study. The flight attendants' official job performance data were provided by the airline company. For data analyses, a series of hierarchical moderated regression analyses were employed. The results showed differential moderation effects of the three sources of support at work. Specifically, the positive relationship between deep acting and job performance was strengthened by perceived supervisor and coworker support. The negative relationship between surface acting and job 
performance was exacerbated by perceived supervisor support, indicating the reverse buffering effect. Perceived organizational support showed only main effects on employee performance with no moderation effects.

(Hur et al., 2015) investigated how emotional labor strategies (i.e. surface acting and deep acting) affect job performance through job satisfaction and to see whether perceived organizational support (POS) moderates the relationship between emotional labor strategies and job-related outcomes (i.e. job satisfaction and job performance) or not. Structural equation modeling analysis provided support for the hypotheses from a sample of 309 South Korean department store sales employees. The authors found that surface acting had a negative effect, whereas deep acting had a positive effect on job satisfaction. In addition, the relationship between emotional labor strategies (i.e. surface acting and deep acting) and job performance was significantly mediated by job satisfaction. Finally, POS significantly moderated the relationship between surface acting and job satisfaction, as well as the relationship between deep acting and job performance. The study contributed to the literature by identifying the relationship between surface and deep acting on organizational outcomes (i.e. job satisfaction and job performance), especially in a collectivist society (i.e. South Korea). Besides, the study also confirmed the important role of POS based on the norm of reciprocity between an organization and its members.

(Edith A. Anomneze et al., 2015) investigated the moderating role of perceived organizational support on emotional labor-burnout relation among 323 secondary school teachers in Enugu State, Nigeria. Participants completed the Teacher Emotional Labor Scale (TELS), Survey of Perceived Organizational Support (SPOS), and Maslach Burnout Inventory (MBI). Results showed that surface acting, deep acting, and POS significantly predicted emotional exhaustion. Only deep acting and POS significantly predicted depersonalization whereas surface acting did not. Both the two-way interaction terms between surface acting and POS, and that between deep acting and POS were not significant in predicting either emotional exhaustion or depersonalization.

(Marchand et al. 2015) examined the time-lagged relationship between perceived organizational support (POS; measured at Time 1), emotional exhaustion (measured six months later), and turnover (measured one year after Time 1), and included negative affectivity (NA) as a moderator. Drawing upon a sample of employees from multiple organizations ( $N=135$ ), the authors found POS to be unrelated to emotional exhaustion but the latter to be negatively related to turnover. NA moderated the relationship between POS and emotional exhaustion and POS'S indirect relationship to turnover, these relationships being stronger and positive at high levels of NA. Moreover, NA moderated the link between emotional exhaustion and turnover, this link being stronger and positive when NA was low. The authors discussed the relevance of conservation of resource theory as a useful framework for interpreting POS's effects.

(Hur et al. ,2013) examined whether and how the perceived organizational support (POS) influences emotional labor and the relationship between emotional labor and flight attendants' outcomes. A Structural equation modeling analysis provided support for the hypotheses from a sample of 256 flight attendants in South Korea. The results showed that POS has a positive effect on deep acting. Furthermore, it was found that surface acting has a positive influence on emotional exhaustion, whereas deep acting has a negative influence on emotional exhaustion. In addition, emotional exhaustion has a negative influence on organizational commitment, while organizational commitment has a negative influence on 
turnover intention. Furthermore, POS moderated the relationship between deep acting or surface acting and emotional exhaustion.

(Burch et al., 2013). This study extends almost three and a half decades of emotional labor research into the study of entrepreneurship by proposing an Affective Entrepreneurial Events Model. Continuing to organizational behavior research and recent, relevant entrepreneurship models, this conceptual model established four areas of understanding. First, it proposed a method by which affect influences the entrepreneurial processes. Second, it demonstrated how what we already know from emotional labor research that can affect the outcomes for entrepreneurs and their stakeholders. Third, it discussed how the entrepreneur's performance of emotional labor shapes the entrepreneurial environment. Lastly, the researchers used the extreme emotional conditions provided by the entrepreneur's environment to further understand the concepts associated with emotional labor.

(Goodwin et al. ,2011) investigated the relationship between the emotional labor strategies surface acting and deep acting and organizational outcomes, specifically, employees' overall job performance and turnover. Call center employees from two large financial service organizations completed an online survey about their use of surface and deep acting. Their responses were matched with supervisors' ratings of overall job performance and organizational turnover records obtained 9 months later. Results indicated that surface acting is directly related to employee turnover and emotional exhaustion and that the relationship between surface acting and job performance is indirect via employee affective delivery. Deep acting was not linked to these outcomes. Theoretical and practical implications were discussed from the perspective of emotional labor theories.

(Humphrey et al., 2008) aimed to argue that leaders perform emotional labor whenever they display emotions in an attempt to influence their subordinates' moods and motivations. It is a conceptual paper that integrates the literature on leadership with the research on emotional labor. The researchers developed 15 propositions that distinguish emotional labor performed by leaders from that performed by front-line service workers. The study suggested that leading with emotional labor is a fruitful research topic, and that considerable research could be done in this area. Findings lead to Instead of conducting business in a non-emotional, "business-like manner", leaders would benefit by expressing their emotions in the workplace. Emotionally expressive leaders are more charismatic and are better motivators.

Clearly, though a considerable amount of effort has been devoted to understanding what emotional labor is, there is a lack of clear definitions and valid measures. The existing study on emotional labor is not far off the subject treated in early study. Also, as researchers are explaining various conceptualizations and processes about emotional labor with quite different theoretical viewpoints, there are problems such as drawing mixed research results. As these researchers are testing diverse precedence factors and result variables on how they define and measure emotion management with opposing sides against one another, it is difficult to measure research results.

Though this is a common phenomenon undergone in the process of theoretical development, for the development of a research on emotional labor, a research to approach emotional labor more synthetically is necessary here and now. Perceiving these problems, this study integrated and refined the conception and variables of emotional labor based on preceding researches. 


\section{Methodology}

\section{Theory and hypotheses development}

\section{The effect of emotional labor on customer satisfaction and customer perceptions}

Research on emotional labor seeks to describe how employees manage their emotions as part of their work roles (Brouwers et al., 2011). Emotional labor entails organizational display rules regardless of one's felt emotions and requires employees to use emotion regulation strategies at work. Most studies have focused on two emotional labor strategies, namely, surface acting and deep acting, which are commonly used for regulating emotional displays at work. Surface acting involves suppressing felt emotions and faking the desired emotions, while deep acting involves actually experiencing the desired emotions.

The aim of using emotional labor strategies is to alter one's emotional displays in order to be consistent with the display rules of one's organization that is because surface acting is "acting in bad faith" (i.e., faking the desired emotion) while deep acting is "acting in good faith" (i.e., trying to experience the desired emotion so that a natural display will follow), these emotion regulation strategies may not have uniform effects on affective and behavioral outcomes.

On the other hand, in today market-oriented business environment, it can be said arguably that the question how to satisfy customers becomes the ultimate concern of most of the companies in any kind of business. In private universities it is the same. Therefore, understanding customer satisfaction (CS) dimensions, measuring it and taking advantage from these measurements become the urgent need for managers and establish the mainstream in academic literature about CS in the recent past. CS is important to be measured because of its significant impacts on firms' long-term performance and also customer purchasing behaviors. In the academics, consistently providing high CS is well acknowledged to be associated with higher customer loyalty and enhanced reputation (Wangnheim \& Bayon, 2004).

CS can also supply a higher barrier against switching to other competitors. Loss cost and move-in cost were positively significant related to the CS (Kim et al. 2004). Exploring the relationship between CS and the economic return is also one of the most interesting topics. (Anderson et al., 1994) attempted to explore the relationship between CS and financial returns using a national customer satisfaction index (NCSI) and ROI (return on investment). They found the significantly positive association between ROI and CS but not immediately realized. (Ittner \& Larcker, 1998) found that CS is a leading indicator of customer purchasing behavior, growth in the number of customers, and accounting performance.

(Yu, 2007) found that "higher CS leads to higher customer revenue and higher customer costs at the same time, and thus customer profits remain unaffected". There is obviously a tradeoff and lead to the question of probability. Thus, in order to achieve more practical implications, CS measurements do not only need to respond to the evaluation of current situation but also being a leading indicator for financial performance.

Therefore, the researcher proposes the following hypotheses:

$\mathrm{H} 1 \mathrm{a}$. Surface acting is negatively related to customer satisfaction. 
$\mathrm{H} 1 \mathrm{~b}$. Deep acting is positively related to customer satisfaction.

$\mathrm{H} 2 \mathrm{a}$. Surface acting is negatively related to customer's perceptions of the work performance of professors and teaching assistants.

$\mathrm{H} 2 \mathrm{~b}$. Deep acting is positively related to customer's perceptions of the work performance of professors and teaching assistants.

\section{Research Variables}

Independent variable: Emotional labor performance

Table 1. Definition of Emotional Labor

\begin{tabular}{|c|c|}
\hline Scholar & Definition \\
\hline $\begin{array}{l}\text { Hochschild } \\
(1983,1989)\end{array}$ & $\begin{array}{c}\text { the management of feeling to create a } \\
\text { publicly observable facial and bodily } \\
\text { display }\end{array}$ \\
\hline $\begin{array}{l}\text { Ashforth\& } \\
\text { Humphrey } \\
\text { (1993) }\end{array}$ & $\begin{array}{c}\text { the act of displaying the appropriate } \\
\text { emotion }\end{array}$ \\
\hline $\begin{array}{l}\text { Morris \& Feldman } \\
\quad(1996,1997)\end{array}$ & $\begin{array}{l}\text { the effort, planning, and control needed to } \\
\text { express organizationally desired emotion } \\
\text { during interpersonal transaction }\end{array}$ \\
\hline $\begin{array}{l}\text { Grandey } \\
(2000)\end{array}$ & $\begin{array}{l}\text { the process of regulating both feelings and } \\
\text { expressions for organizational goals }\end{array}$ \\
\hline $\begin{array}{l}\text { Krual\& Geddes } \\
\quad(2000 \mathrm{a})\end{array}$ & $\begin{array}{l}\text { what employees perform when they are } \\
\text { required to feel or at least project the } \\
\text { appearance of certain emotions in order to } \\
\text { produce }\end{array}$ \\
\hline $\begin{array}{l}\text { Diefendorff\& } \\
\text { Richard(2003) }\end{array}$ & $\begin{array}{l}\text { the management of emotions as part of the } \\
\text { work role }\end{array}$ \\
\hline $\begin{array}{l}\text { Johnson } \\
\text { (2007) }\end{array}$ & $\begin{array}{l}\text { the expression of organizationally desired } \\
\text { emotions by service agents during service } \\
\text { encounters }\end{array}$ \\
\hline
\end{tabular}

Emotional labor was first defined by (Hochschild 1983) as "the management of feeling to create a publicly observable facial and bodily display" in the context of service work. Three principal characteristics of jobs involving emotional labor are they:

- Require face to face or voice to voice contact with the public.

- Require the worker to produce an emotional state in another person (i.e., client or customer).

- Allow employers, through training and supervision, to exercise a degree of control over the emotional activities of employees.

(Ashforth \& Humphrey, 1993) offered a perspective operationalizing emotional labor as "the act of displaying the appropriate emotion." They reframe Hochschild's notion of feeling rules as display rules. This modification emphasizes external observable behavior (i.e., that which is displayed) rather than the internal emotional experience (i.e., that which is felt) of the service worker. Refocusing from the internal to the external decouples the experience of emotion from the expression of emotion. 
(Morris \& Feldman, 1996) Defined emotional labor as "the effort, planning, and control needed to express organizationally desired emotion during interpersonal transactions" they claim a view rooted in an interactionist model of emotion.

\section{Surface Acting (SA) \& Deep Acting (DA)}

SA involves employees simulating emotions that are not actually felt, by changing their outward appearances (i.e., facial expression, gestures, or voice tone) when exhibiting required emotions. Using the SA technique, people alter the outward expression of emotion in the service of altering their inner feelings. By changing facial or bodily expressions, such as slumped shoulders, bowed head, of drooping mouth, inner feelings can be altered to a corresponding state (Hochschild, 1993).

DA occurs when employees' feelings do not fit the situation; they then use their training or experience to work up appropriate emotions. Unlike SA, DA involves changing inner feelings by altering something more than outward appearance. In SA, feelings are changed from "outside in", whereas feelings are changed from the "inside out" in DA (Hochschild, 1993). (Hochschild,1983) classified DA as (1) exhorting feeling, whereby one actively attempts to evoke or suppress an emotion, and (2) trained imagination, whereby one actively invokes thoughts, images, and memories to induce the associated emotion(thinking of a wedding to feel happy or a funeral to feel sad). In other words, employees use their training or experiences to help conjure up appropriate emotions or responses (empathy, cheerfulness) for a given scene (Kruml\& Geddes, 2000a).

The two strategies suggested by (Hochschild ,1983), Deep Acting (DA) and Surface Acting (SA), have a common ground in that they both are a kind of complementary emotional labor strategy that employees use when they cannot naturally express their emotion (Diefendorff et al., 2004), and both the two let employees perform emotional labor in the same way as normative emotion that an organization requires them to express to customers (Grandey, 2003). However, intentions of the two strategies are definitely different from each other.

$\mathrm{SA}$ is to make only the visual aspect of employees' emotion correspond to the emotional expression principle of an organization. Accordingly, emotional dissonance could be easily induced (Grandey, 2003)

DA is not only to create externally expressed emotion but to change internal emotion in the direction of the emotional expression principle. For this, empathy, and thoughts and images that trigger specific emotion are actively utilized (Grandey, 2003).

The two emotional labor strategies suggested by (Hochschild,1983), DA and SA, have a common ground that both the two attempt to perform emotional labor in the same way as normative emotion that an organization requires employees to express, when they cannot appropriately express their emotion (Grandey, 2003).

However, these two emotional labor strategies have a clear difference. The SA strategy attempts to make only external expressions correspond to normative emotion required by an organization regardless of employees' internal emotion. This could cause emotional dissonance due to conflicts between employees' internal feeling and normative emotion. In this light, the SA strategy is different from the DA strategy, and can be named 'fake in bad faith'. The DA strategy tries to change even employee's internal emotion in the direction of normative emotion. In this regard, the DA strategy can be named 'fake in good faith'. 
Existing studies showed that SA results in negative emotional labor and DA results in positive emotional labor. For example, they reported that while SA is related to negative results such as depersonalization, emotional exhaustion, or dissatisfaction, DA is related to positive results such as sincerity or a sense of fulfillment.

DA and SA have different results and effectiveness. That is, because while DA is not only to create externally expressed emotion but to change even internal emotion in the direction of the emotional expression principle, SA is only to make the visual emotional aspect correspond to the organizational emotional expression principle (Hochschild, 1983), DA is highly relevant to a positive outcome variable and SA is highly relevant to a negative outcome variable.

There is a conceptual model by using emotion regulation theory through characterizing emotional labor. Gross suggested this emotion regulation theory (1998), which indicates 'the process that influences what emotion individuals have, when they feel that emotion, how they experience emotion, and how they express it'. The importance of SA and DA during the process of performing emotional labor. The argue is that SA and DA could bring about both positive and negative results upon emotional labor. For example, SA could have a negative effect on job satisfaction due to the discord that individuals experience. On the other hand, DA could positively influence job satisfaction because it makes individuals feel a sense of fulfillment that they have expressed their emotion appropriately. It includes not only the outcome variable of emotional labor but situational, individual, and organizational factors that influence emotional labor.

\section{Dependent Variable \\ Customer Satisfaction}

The concept of customer satisfaction occupies a central position in marketing thought and practice. Satisfaction is a major outcome of marketing activity and serves to link processes culminating in purchase and consumption with post purchase phenomena such as attitude change, repeat purchase, and brand loyalty. The centrality of the concept is reflected by its inclusion in the marketing concept that profits are generated through the satisfaction of consumer needs and wants. The need to translate the philosophical statement of the marketing concept into pragmatic operational guidelines has directed attention to the development and measurement of customer satisfaction.

In the early 1970s, customer satisfaction began to emerge as a legitimate field of inquiry. The U.S. Department of Agriculture's Index of customer Satisfaction (Pfaff, 1972) was the first study to report direct information on customer satisfaction to policy makers. Since the early 1970s the volume of customer satisfaction research has been impressive. Numerous theoretical structures have been proposed to examine the antecedents of satisfaction and develop meaningful measures of the construct. The vast majority of these studies have used some variant of the disconfirmation paradigm which holds that satisfaction is related to the size and direction of the disconfirmation experience, where disconfirmation is related to the person's initial expectations.

\section{Customer Perceptions}


Customer perception is a "Marketing concept that encompasses a customer's impression, awareness, or consciousness about a company or its offerings."

Customer collects information about a product and interprets the information to make a meaningful image about a particular product. This is called as customer perception.

In this study, the researcher ran a context analysis about emotional labor performance identifying the barriers and facilitators that professors encounter during their work. Through the strategies surface acting and deep acting, by considering the right issues and facilitators and barriers, the faculty will better understand how to plan and manage them to end up in better conditions to reach the expected customer satisfaction and perceptions of the work performance of employees.

\section{The Proposed Research Model}

The research hypotheses can be represented by the following model figure (1)

A-Independent variables: Emotional Labor Performance (Surface acting and deep acting)

B-Dependent variables: (customer's satisfaction and customer's perception)

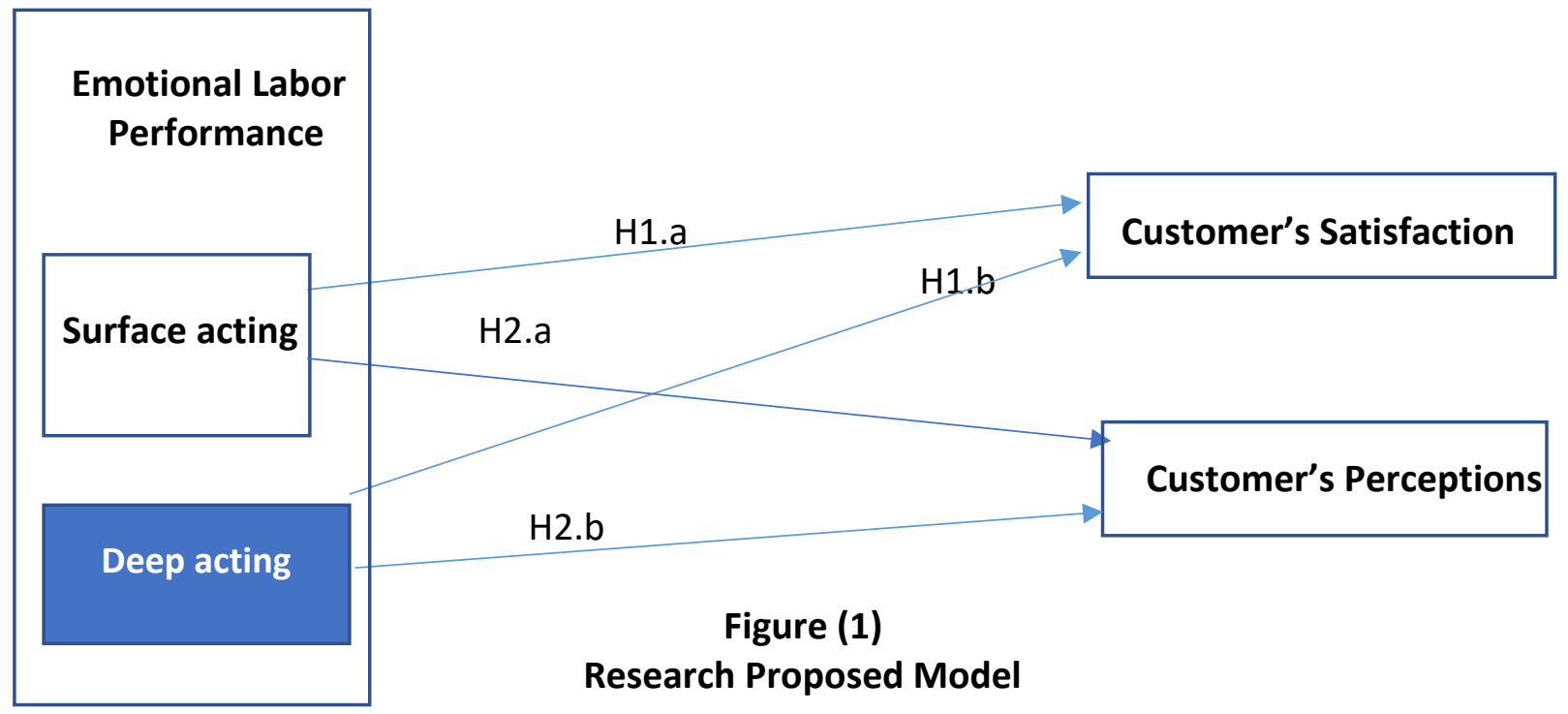

\section{Research Design}

\section{Design of the questionnaire}

As a basis for this research, the researcher built 2 questionnaires one to measure the customer satisfaction, customer perception, beside the benefits for both customers and businesses. And a second was assessed with the Surface Acting and Deep Acting subscales to measure emotional labor. This research was conducted in electronic databases such as Elsevier, Science Direct, Springer, Google Scholar, and academic textbooks. Subsequently, a pilot test was conducted applying the questionnaire to 30 students' studying in different universities in Egypt.

The first questionnaire was divided into three sections, with a total of 30 questions related to customer satisfaction, customer's perception, in addition to the personal questions. The 
second one was delivered to professors and teaching assistants and it was divided into three sections.

\section{Data Collection Process}

The final questionnaires were administered in print and electronically via the tool Survey Monkey. The researcher sent it to 300 students in the Faculty of Business and Economics at Badr University, and 20 professors and teaching assistants. The aim of the survey was explained and the students were invited to participate in the research. Suitable students to answer the questionnaire were: level one, two, three and four in all tracks.

\section{Measures}

\section{Emotional Labor}

Emotional labor was assessed through (Surface Acting and Deep Acting) subscales of (Çukur's ,2009) Teacher Emotional Labor Scale (TELS), which was specifically designed to measure emotional labor that teachers experience in the course of their interactions with students, coworkers and supervisors while discharging their duties. Both subscales contain five items each. Ratings were made using a 5-point scale, ranging from 1 (not at all) to 5 (very true). Items on both the Surface Acting and Deep Acting subscales of the TELS were slightly modified in the present study such that the terms 'your' was replaced with 'my', while 'you' was replaced with ' $l$ ' or ' $m e^{\prime}$ ', in order to refer more directly to the particular professor responding to the items. Sample items include "I try to control my feelings to have emotions I need to display for my job when sharing sad news with students", and "I try to put an effort to actually feel the emotion I need to display when discussing frequently with students about grades", for the Surface Acting and Deep Acting subscales, respectively.

\section{Customer satisfaction and Customer perceptions}

The SERVQUAL method was suggested to evaluate CS by (Parasuraman et.al, 1998). The central idea in this model is that service quality is primarily a function of the difference scores or gaps between expectations and perceptions (Jamali, 2007). The service quality research has been dominated by the SERVQUAL instrument which is usually cluster in five group quality determinants: Reliability, Responsiveness, Assurance, Empathy and Tangible (Wisniewski, 2001).

\section{Results and Conclusion}

This section highlights the main findings of the study in a cohesive manner. It reviews the research background and findings, followed by recommendations for professors and teaching assistants, and concludes with future research ideas.

Cronbach's alpha $(\alpha)$ of .73 and .72 were obtained for the Surface Acting and Deep Acting subscales of the TELS, respectively, in the present study. Higher scores on either of these subscales indicate that the professor and teaching assistants made greater use of surface acting than deep acting in the process of discharging his or her duties.

The initial survey contained 63 items. Three researchers (two familiar with the literature and one unfamiliar) sorted like items into five groups. Of the items, 26 dealt with acknowledgment, control, or manipulation of emotions during service encounters and were thus believed to tap the acting-based emotional labor construct. 
Of the remaining items, 25 represented possible antecedent variables identified in previous emotional labor research and seen as relevant for an emerging model of emotional labor. These items appeared to fall naturally into four groups: (a) the company's focus on quality versus quantity of interactions, (b) degree of latitude professors and teaching assistants feel they have when displaying emotions to students, (c) whether students are pleasant or unpleasant, and (d) training and guidance on how to deal with students' emotions. A 5-point Likert-type response scale was used for the items ( 1 = never to $5=$ always). The remaining 12 items captured demographic and relevant job (e.g., job and occupational tenure) information.

\section{Test the Hypotheses of the Model Structure \\ Presenting the Results from Correlation}

The results using Pearson correlation could be presented in a research report as follows.

For hypotheses $\mathrm{H} .1 \mathrm{a}$ which predicted that Surface acting is negatively related to customer satisfaction. Regarding H.1a this result seems to be accepted for the following: The relationship between Surface acting and customer satisfaction was investigated using Pearson product-moment correlation coefficient. Preliminary analyses were performed to ensure no violation of the assumptions of normality, linearity and homoscedasticity. There was a strong negative correlation between the two variables as follows: Where r refers to the strength of correlation, $p$ refers to confidence level, while $n$ is the number of cases and $R$ square is the amount of confidence.

$r=.88$ in students of level one, $n=220, p<.0005,1.00$ in students of level two indicates a perfect positive correlation $n=180, p<.0005$, .98 in students of level three, $n=150, p<.0005$ and .96 in students of level four, $n=120, p<.0005$, with high levels of Surface acting associated with high levels of the customer satisfaction.

For hypotheses H.1b which predicted that Deep acting is positively related to customer satisfaction. Regarding H.1b this result seems to be accepted for the following:

- The relationship between Deep acting and customer satisfaction was investigated using Pearson product-moment correlation coefficient. Preliminary analyses were performed to ensure no violation of the assumptions of normality, linearity and homoscedasticity. There was a strong, positive correlation between the two variables, $r=.93$ in students of level one, $n=220, p<.0005 . r=1.00$ in student of level two, $n=180, p=<.0005 . r=.94, n=150, p<.0005$ in students of level three, $n=150, p<.0005$ and .93 in students of level four, $n=120, p<$ .0005 , with high levels of deep acting associated with high levels of the customer satisfaction.

For H2 a. Surface acting is negatively related to customer's perceptions of the work performance of professors and teaching assistants. The results showed that:

- The relationship between Surface acting and customer's perceptions was investigated using Pearson product-moment correlation coefficient.

- Preliminary analyses were performed to ensure no violation of the assumptions of normality, linearity and homoscedasticity. There was a strong, positive correlation between the two variables, $r=.65$ in students of level one, $n=220, p<.0005, r=1.00$ in students of level two because at least one of the variables is constant $n=180, p<.0005, .81$ in students of level three, $n=150, p<.0005$ and .77 in students of level four, $n=120, p<.0005$, with high levels of Surface acting associated with high levels of the customer's perceptions. 


\section{H2 b. Deep acting is positively related to customer's perceptions of the work performance} of professors and teaching assistants. The results showed that:

- The relationship between Deep acting and customer's perceptions was investigated using Pearson product-moment correlation coefficient.

- Preliminary analyses were performed to ensure no violation of the assumptions of normality, linearity and homoscedasticity. There was a strong, positive correlation between the two variables, $r=.73$ in students of level one, $n=220, p<.0005, r=1.00$ in students of level two because at least one of the variables is constant $n=180, p<.0005, .86$ in students of level three, $n=150, p<.0005$ and.88 in students of level four, $n=120, p<.0005$, with high levels of Deep acting associated with high levels of the customer's perceptions.

\section{Regression}

\section{Step 1: Checking the Assumptions Multicollinearity}

According to (Pallant, 2011), this refers to the relationship among the independent variables. Multicollinearity exists when the independent variables are highly correlated ( $r=.9$ and above).

The correlations between the variables in the model are provided in the table labeled Correlations. The independent variables show strong positive relationship with the dependent variable as presented before for each student's level.

The results are presented in the table labeled Coefficients. Two values are given: Tolerance and VIF. Tolerance is an indicator of how much of the variability of the specified independent is not explained by the other independent variables in the model and is calculated using the formula 1-R squared for each variable. In this study, all variables are performed with the multicollinearity test and the results demonstrate the low inter-correlation between independent variables with all the VIF values less than 10.

\section{Step 2: Evaluating the model}

According to (Pallant, 2011), from the Model Summary box the value given under the heading $\mathrm{R}$ Square that tells how much of the variance in the dependent variable. The Emotional labor is explained by the model. In this case, the value is.808 in students of level one , 1.00 in students of level two , .944 in students of level three and .922 in students of level four. Expressed as a percentage this means that our model explains 80 percent in level one, $100 \%$ in level two , 94\% in level three and $92 \%$ in level four of the variance in Emotional labor. This is quite a respectable result (particularly when we compare it to some of the results that are reported in the journals!).

To assess the statistical significance of the result, it is necessary to look in the table labeled ANOVA. This tests the null hypothesis that multiple $\mathrm{R}$ in the population equals 0 . The model in this research reaches statistical significance (Sig. $=.000$; this really means $p<.0005$ ).

The Sig. value of the independent sub-variable customer satisfaction 000 which is less than 0.05 , the variable is making a significant unique contribution to the prediction of the dependent variable in level one, level three and level four. 


\section{Step 3: Evaluating Each of the Independent Variables}

To know the contribution of each independent variable; the researcher used the beta values in the comparison. By looking down the Beta column to find which beta value is the largest (ignoring any negative signs out the front).

In this study the largest beta coefficient is .934, which is for surface acting. This means that this variable makes the strongest unique contribution to explaining the dependent variable, when the variance explained by all other variables in the model is controlled for. The Beta value for customer satisfaction was slightly lower .523, indicating that it made less of a unique contribution.

In this case the largest beta coefficient is .933 , which is for surface acting in students of level three. This means that this variable makes the strongest unique contribution to explaining the dependent variable, when the variance explained by all other variables in the model is controlled for. The Beta value for customer satisfaction was slightly lower .523, indicating that it made less of a unique contribution.

The Sig. value of the independent sub-variable customer perception 000 which is less than .0 .05 , the variable is making a significant unique contribution to the prediction of the dependent variable in level one, level three and level four. For models with dependent variable of surface and deep acting, the following variables are constants or have missing correlations in the students of level two: customer perception. They will be deleted from the analysis; therefore, Statistics cannot be computed.

\section{Conclusion}

These findings illustrate the importance of this study for higher education field, human resource (HR) managers, and career counsellors, as it gives insight into the relationship between emotional labor performance through surface and deep acting with customer satisfaction and customer perceptions of the work performance of professors and teaching assistants as performance ratings.

\section{Contribution}

This is the first paper to develop a theoretical model that describes emotional labor in higher Education; thus the propositions are original.

\section{Research limitations/implications}

The main limitations were linked with the source of the data as the researcher worked with a convenience sample and only analyzed the information provided by the customers (Students of

Faculty of Business and Economics at Badr University).

Second, the cross-sectional design of the study did not allow for causal inferences. As previously noted, it is possible that professors and teaching assistants may feel more emotionally exhausted if they do not see much success in their students' learning despite their own teaching engagement.

Finally, a third limitation already mentioned above is that the researcher was not able to shed light on the mediating processes that explain the association between professors' emotions and students' satisfaction and perception. Overall, this study underlines the importance of professors' deep acting for students' satisfaction and perception that professors' surface acting symptoms are not only associated with important professor related outcomes, such as 
health impairments or job turnover, but also with important student outcomes. This finding highlights the importance of professors well-being and of intervention programs (e.g., Roeser et al., 2013) to reduce professor stress and surface acting symptoms.

\section{Future Research}

The researcher recommends that the same questionnaire be applied to other faculties, both inside and outside Cairo, to explore and find better answers with respect to the relationship between surface and deep acting with customer satisfaction and customer perception.

It would be also advisable to consider other fields in order to analyze these relationship and compare the results from another perspective.

\section{References}

Anderson, E., \& Fornell, C. (2000). Foundations of The American Customer Satisfaction Index. Total Quality Management, 11(7), 869-882. http://dx.doi.org/10.1080/09544120050135425

Anderson, E., Fornell, C., \& Lehmann, D. (1994). Customer Satisfaction, Market Share, and Profitability: Findings from Sweden. Journal of Marketing, 58(3), 53-66. http://dx.doi.org/10.2307/1252310

Anita B. P.(1972),"An Index of Consumer Satisfaction", in SV - Proceedings of the Third Annual Conference of the Association for Consumer Research, eds. M. Venkatesan, Chicago, IL: Association for Consumer Research, Pages: 713-737.

Ashforth, B., \&Humphrey, R. (1993). Emotional labor in service roles: The influence of identity. Academy of Management Review, 18, 88-115.

Bakker, A. B., Demerouti, E., \& Verbeke, W. (2004). Using the job demands-resources model to predict burnout and performance. Human Resource Management, 43(1), 83-104. http://dx.doi.org/10.1002/hrm

Brouwers, A., Tomic, W., \& Boluijt, H. (2011). Job demands, job control, social support and self-efficacy beliefs as determinants of burnout among physical education teachers. Europe's Journal of Psychology, 7(1), 17-39. http://dx.doi.org/10.5964/ejop.v7i1.103

Costa, P. L., Passos, A. M., and Barata, M. C. (2015), "Multilevel influences of team viability perceptions", Team Performance Management, Vol. 21 Nos 1/2, pp. 19-36, available at: http://doi.org/http://dx. doi.org/10.1108/TPM-07-2014-0042

Cukur, C. S. (2009). The development of the Teacher Emotional Labor Scale (TELS): Validity and reliability. Kuram ve Uygulamada Eğitim Bilimleri, 9(2), 559-574.

Diefendorff, J. M., \& Richard, E. M. (2003). Antecedents and consequences of emotional display rule perceptions. Journal of Applied Psychology, 88(2), 284294. https://doi.org/10.1037/0021-9010.88.2.284

Endres, M. L., and Rhoad, K. T. (2016), "What makes a high performer share knowledge?", Team Performance Management, Vol. 22 Nos 5/6, pp. 269-283, available at: http://doi.org/10.110 8/TPM-05-2016-0022

Grandey, A. A. (2000). Emotion regulation in the workplace: A new way to conceptualize emotional labor.

Grandey, A. A. (2003). When "The show must go on": Surface acting and deep acting as determinants of emotional exhaustion and peer- rated service delivery. Academy of Management Journal, 46(1), 86-96. 
Henttonen, K., Kianto, A., \& Ritala, P. (2016). Knowledge sharing and individual work performance: an empirical study of a public sector organisation. Journal of Knowledge Management, 20(4), 749-768.

Hobfall, S. E. (2001). The influence of culture, community, and the nested-self in the stress process: Advancing conservation of resources theory. Applied Psychology: An International Review, 50(3), 337-421.http://dx.doi.org/10.1111/1464-0597.00062

Hochschild, A. R. (1983). The managed heart: Commercialization of human feeling. Berkeley, CA: University of California Press.

Hochschild, A. R. (1989). Reply to Cas Wouters' review essay on the managed heart. Theory, Culture, and Society, 6(3),439-445.http://dx.doi.org/10.1016/j.telpol.2003.12.003

Humphrey, R. H., Pollack, J. M., and Hawver, T. (2008), "Leading with emotional labor", Journal of Managerial Psychology, Vol. 23 No. 2, pp. 151-168.

Hussain, K., Konar, R., \& Ali, F. (2016). Measuring Service Innovation Performance through Team Culture and Knowledge Sharing Behaviour in Hotel Services: A PLS Approach. Procedia-Social and Behavioral Sciences, 224, 35-43.

Ittner, C., \& Larcker, D. (1998). Are Nonfinancial Measures Leading Indicators of Financial Performance? An Analysis of Customer Satisfaction. Journal of Accounting Research, 36(1), 1-35.at : http://dx.doi.org/10.2307/2491304

Jamali, D. (2007). A study of customer satisfaction in the context of a public private partnership. International Journal of Quality \& Reliability Management, 24(4), 370385. http://dx.doi.org/10.1108/02656710710740545

Jamshed, S. (2018). EMOTIONALLY INTELLIGENT TEAMS: CAN EMOTIONAL INTELLIGENCE ENHANCE PERFORMANCE. Kuwait Chapter of the Arabian Journal of Business and Management Review, 7(1), 23-33.

Johnson, H.-A. M., \& Spector, P. E. (2007). Service with a smile: Do emotional intelligence, gender, and autonomy moderate the emotional labor process? Journal of Occupational Health Psychology, 12(4), 319-333. https://doi.org/10.1037/10768998.12.4.319

Kim, M., Park, M., \& Jeong, D. (2004). The Effects of Customer Satisfaction and Switching Barrier on Customer Loyalty in Korean Mobile Telecommunication Services. Telecommunications Policy, 28(2), 145-159.

Kruml, S., \& Geddes, D. (in press). Catching fire without burning out: Is there an ideal way to perform emotion labor? In N. M. Ashkanasy, C.E.J. Hartel, \& W. J. Zerbe (Eds.), Emotions and organizational life. Westport, $\mathrm{CT}$ :

Moon, T. W., Hur, W. M., \& Jun, J. K. (2013). The role of perceived organizational support on emotional labor in the airline industry. International Journal of Contemporary Hospitality Management, 25(1), 105123.http://dx.doi.org/10.1108/09596111311290246

Morris, J., \& Feldman, D. (1997). Managing emotions in the workplace. Journal of Managerial Issues, 9, 257-274.

Morris, J.,\&Feldman, D. (1996). The dimensions, antecedents, and consequences of emotional labor. Academy of Management Review, 21, 986-1010.

Oropesa Vento, M., García Alcaraz, J.L., Maldonado Macías, A.A. and Martínez Loya, V. (2016), "The impact of managerial commitment and Kaizen benefits on companies", Journal of Manufacturing Technology Management, Vol. 27 No. 5, pp. 692712. 
Oropesa-Vento, M., García-Alcaraz, J.L., Rivera, L. and Manotas, D.F. (2015), “Effects of management commitment and organization of work teams on the benefits of Kaizen: planning stage", Dyna, Vol. 82 No. 191, pp. 76-84, available at: http://doi.org/10.15446/dyna.v82n191.51157

Pais, C. A., and Parente, C. (2015), "Representations of team work among organizations with a social entrepreneurship profile a multiple case-study", Team Performance Management, Vol. 21 Nos 1/2, pp. 65-84, available at: http://doi.org/10.1108/TPM-072014-0042

Pallant A. (2011) The Molecular Workbench Software: An Innovative Dynamic Modeling Tool for Nanoscience Education. In: Khine M., Saleh I. (eds) Models and Modeling. Models and Modeling in Science Education, vol 6. Springer, Dordrecht. https://doi.org/10.1007/978-94-007-0449-7_6

Parasuraman, A., Zeithaml, V., \& Berry, L. (1998). SERVQUAL: A Multiple-item Scale for Measuring Consumer Perceptions of Service Quality. Journal of Retailing, 64(1), 12-37.

Pugh S. D. (2001). Service with a smile: Emotional contagion in the service encounter. Academy of Management Journal, 44(5), 1018- 1027

Ritala, P., Olander, H., Michailova, S., \& Husted, K. (2015). Knowledge sharing, knowledge leaking and relative innovation performance: An empirical study. Technovation, 35, 2231.

Roeser, R. W., Schonert-Reichl, K. A., Jha, A., Cullen, M., Wallace, L., Wilensky, R., Oberle, E., Thomson, K., Taylor, C., \& Harrison, J. (2013). Mindfulness training and reductions in teacher stress and burnout: Results from two randomized, waitlist-control field trials. Journal of Educational Psychology, 105(3), 787-804. https://doi.org/10.1037/a0032093

Sağ, S., Kaynak, R., \& Sezen, B. (2016). Factors Affecting Multinational Team Performance. Procedia-Social and Behavioral Sciences, 235, 60-69.

Samia Jamshed, Mohammad Nazri, Raida Abu Bakar, (2018),"The Effect of Knowledge Sharing on Team Performance through Lens of Team Culture ", DOI: 10.12816/0049504

Wang, C.-J. (2019), "From emotional labor to customer loyalty in hospitality: A three-level investigation with the JD-R model and COR theory", International Journal of Contemporary Hospitality Management, Vol. 31 No. 9, pp. 37423760. https://doi.org/10.1108/IJCHM-01-2019-0072

Wangenheim, F., \& Bayón, T. (2004). Satisfaction, loyalty and word of mouth within the customer base of a utility provider: Differences between stayers, switchers and referral switchers. Journal of Consumer Behaviour, 3(3), 211-220. http://dx.doi.org/10.1002/cb.135

Wisniewski, M. (2001), "Using SERVQUAL to assess customer satisfaction with public sector services", Managing Service Quality: An International Journal, Vol. 11 No. 6, pp. 380388. https://doi.org/10.1108/EUM0000000006279

Wood, A. (2003), "Managing employees' ideas from where do ideas come?", Journal for Quality \& Participation, Vol. 26 No. 2, p. 22.

Yu, S. (2007). An Empirical Investigation on the Economic Consequences of Customer Satisfaction. Total Quality Management \& Business Excellence, 18(5), 555-569. http://dx.doi.org/10.1080/14783360701240493 